\title{
A new approach to improve water loss control using smart metering data
}

D. Loureiro, H. Alegre, S. T. Coelho, A. Martins and A. Mamade

\begin{abstract}
$\overline{\text { ABSTRACT }}$
The control of water losses is a major concern in the sustainability of urban water utilities and in promoting the efficient use of this natural resource. Recent advances in telemetry technology provide high-resolution consumption data at the consumer level, allowing for a remarkable knowledge improvement on the different water balance components. However, few studies focus on systematic approaches for improving system operation and maintenance by processing and analysing large amounts of consumption data. This paper presents a new methodology to calculate real losses and apparent losses in distribution networks using data collected from telemetry systems. The methodology proposes a set of algorithms that are simple to implement. These algorithms were tested on different district metered areas (DMA) to improve understanding about water loss components and have already been included in commercial software. The results showed that these algorithms are robust and allow for accurately estimating the background leakage level (and unreported leaks and bursts), detecting earlier the occurrence of bursts and providing important insights into the type of illegal water uses. The use of these approaches reduced non-revenue water by more than $10 \%$ in the majority of the DMA tested. These findings are promising and demonstrate the strong potential of telemetry systems to reduce water losses and to improve the understanding of water uses.
\end{abstract}

Key words | apparent losses, real losses, smart metering, water consumption, water losses

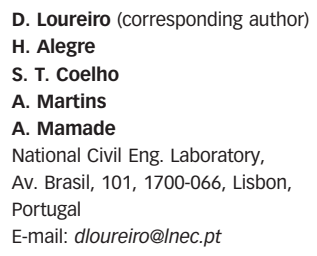

